\title{
LA ESPACIALIDAD ESCOLAR, LECTURAS EN FOCO Y DESPLAZAMIENTOS EN LA (DE)CONSTRUCCIÓN DE UN OBJETO
}

\author{
ALEJANDRA MARÍA CASTRO ${ }^{1}$ \\ ORCID: https://orcid.org/0000-0002-1004-6593
}

\begin{abstract}
RESÚMEN: El espacio escolar es una dimensión sustantiva de las formas y las culturas escolares que necesita ser abordado en su complejidad y en las (des)articulaciones con procesos pedagógicos, sociales y culturales de las instituciones educativas, las políticas educativas y el contexto social. En este trabajo se presentan, en una primera parte, algunas perspectivas teórico-metodológicas y categorías analíticas con el propósito de ampliar y profundizar en su conocimiento. Estas herramientas se construyeron con aportes de las ciencias sociales, en particular de la geografía crítica y postestructuralista, en un proceso que incluye, asimismo, intervenciones y reflexiones interdisciplinarias entre pedagogos, arquitectos y diseñadores industriales en el marco de proyectos de investigación en la Universidad Nacional de Córdoba. En una segunda parte, se ponen en juego estas categorías analíticas con los procesos de escolarización y se plantean algunas reflexiones e interrogaciones en torno a los desafíos que implica la ampliación de derecho a la educación en clave espacial.
\end{abstract}

Palabras clave: Espacios escolares, producción del espacio, derecho a la educación, espacialidad escolar.

\section{ESPACIALIDADE ESCOLAR, LEITURAS DE FOCO E DESLOCAMENTOS NA (DES) CONSTRUÇÃO DE UM OBJETO}

RESUMO: O espaço escolar é uma dimensão substantiva das formas e das culturas escolares que precisa ser abordadas em sua complexidade e nas (des)articulações com os processos pedagógicos, sociais e culturais das instituições escolares, as políticas educacionais e o contexto social. Neste trabalho apresenta-se, inicialmente, algumas perspectivas teórico-metodológicas e categorias analíticas com o propósito de ampliar e aprofundar esse conhecimento. Essas ferramentas foram construídas a partir das ciências sociais e, particularmente, da geografia crítica e pós-estruturalista, num processo que também incluiu intervenções e reflexões interdisciplinares entre pedagogos, arquitetos y designs industriais no âmbito de projetos de pesquisa na Universidade Nacional de Córdoba. $\mathrm{Na}$ segunda parte do trabalho, essas categorias analíticas são articuladas e problematizadas com os processos de escolarização e levanta-se algumas reflexões e

\footnotetext{
${ }^{1}$ Doctora en Ciencias de la Educación, profesora Titular de la Escuela de Ciencias de la Educación e investigadora del Centro de Investigaciones "Maria Saleme de Burnichon", Facultad de Filosofía y Humanidades, Universidad Nacional de Córdoba, Argentina. <alecastrosanuy@gmail.com>
} 
questionamentos relacionados aos desafios postos à ampliação do direito à educação considerando a dimensão espacial.

Palavras chave: Espaços escolares, produção do espaço, direito à educação, espacialidade escolar.

\title{
SCHOOL SPATIALITY, READINGS IN FOCUS AND DISPLACEMENTS IN THE (DE)CONSTRUCTION OF AN OBJECT
}

\begin{abstract}
The school space is a substantive dimension of school forms and cultures that needs to be approached in its complexity and (dis)articulations with pedagogical, social and cultural processes of educational institutions, educational policies and the social context. In this paper we present, in a first part, some theoretical-methodological perspectives and analytical categories with the purpose of broadening and deepening their knowledge. These tools were built with contributions from the social sciences, particularly from critical and post-structuralist geography, in a process that also includes interdisciplinary interventions and reflections among pedagogues, architects and industrial designers in the framework of research projects at the National University of Córdoba. In a second part, these analytical categories are put into play with the processes of schooling and some reflections and questions are raised about the challenges involved in the expansion of the right to education in spatial terms.
\end{abstract}

Key words: School spaces, production of space, right to education, school spatiality. 


\section{INTRODUCCIÓN}

Yo creo que soy extremadamente nómade. Quiero decir, rápidamente transformo lo que encuentro en una habitación. Si queremos hablar de la idea de hogar menos personalmente y más filosóficamente, de inmediato pienso en el rumano Mircea Eliade... Él tiene una definición de hogar que me agrada mucho. Afirma que es el punto en el que se cruzan una línea vertical y una línea horizontal. La línea horizontal es la línea de los intercambios en todo el sentido de la palabra: es geográfica y es lo que da pie a los intercambios del mundo. Y la línea vertical está entre los muertos y el cielo. Si los muertos están allí o no, la creencia está en uno. Ese es el pequeño punto que llamamos hogar: exactamente donde la línea de los intercambios cruza lo metafísico y lo eterno. (John Berger, 2007, p.50)

Presentamos en este escrito algunas exploraciones que, desde la investigación ${ }^{2}$, venimos construyendo a nivel teórico-conceptual y analítico sobre los procesos de escolarización en el marco de la obligatoriedad escolar y el derecho a la educación. Con la sanción de la ley de Educación Nacional N² 26.206 en el año 2006 en Argentina, que reconoce la educación como derecho personal y social, como un bien público, no transable y garantizado por el Estado, se modifica de forma estructural la extensión de la obligatoriedad de los trayectos educativos, tanto de la Educación Inicial, siendo obligatorias las salas de 4 y 5 años, como de la Educación Secundaria, obligatoria en su totalidad. En cuanto a la Educación Primaria, se amplía el tiempo de permanencia de los estudiantes en la escuela, a través de la Jornada Extendida, que se implementa a contraturno.

Nuestro proyecto de investigación se propone estudiar los procesos de escolarización que se están desplegando, desde la sanción de la mencionada normativa, para garantizar el derecho a la educación y la obligatoriedad, específicamente de la escuela secundaria, y poder dar cuenta de acciones y decisiones que colaboran, favorecen u obstaculizan garantizar este derecho, tanto a nivel de las políticas ministeriales como de las instituciones educativas. Dar cuenta de estos procesos implica considerar la complejidad que se pone en juego en la implementación de políticas públicas educativas. Concebimos que los procesos que se desagregan para garantizar el derecho a la educación son variados, comprometen diferentes escalas y están atravesados por las tensiones, conflictos, diversidad de intereses y poder -capacidad de negociación e influencia- de los diferentes actores sociales implicados. En nuestra investigación proponemos estudiar de forma relacional lo planteado en las normativas, las políticas de inclusión educativa, y los aspectos vinculados a las formas de organización de la escuela secundaria en relación a este mandato jurídico de educación secundaria obligatoria. La hipótesis central que se sustenta, y que nos ha posibilitado una lectura compleja de los procesos educativos, es que el estudio de las políticas educativas y de los cambios inducidos desde el Estado, requieren un análisis simultáneo de las regulaciones oficiales que se despliegan para el sistema en su conjunto y de los procesos de traducción, resignificación y asignación de sentidos que los sujetos de las instituciones educativas producen sobre estas regulaciones.

\footnotetext{
2 Actualmente estamos desarrollando dos investigaciones que incluyen en sus equipos investigadores, docentes y estudiantes de la Facultad de Filosofía y Humanidades y de la Facultad de Arquitectura, Urbanismo y Diseño de la Universidad Nacional de Córdoba, Argentina. Uno de los estudios se denomina "El derecho a la escolarización secundaria. Aportes para la (de)construcción de las condiciones de escolarización y el formato escolar", y el otro estudio se trata de un programa que se titula "Educación y espacialidad. Interacción entre pedagogía, arquitectura y políticas en la construcción de espacios educativos". Ambos estudios han sido aprobados y cuentan con subsidio de la Secretaría de Ciencia y Tecnología de la Universidad Nacional de Córdoba, 2018-2021
} 
En este artículo, compartimos algunas reflexiones sobre la dimensión espacial en estos procesos de escolarización. Esta dimensión, es abordada en los últimos años en estudios e investigaciones tanto del campo educativo como el arquitectónico (Castro y Oliva, 2020; Serra y Trlin, 2017; Cattaneo y Espinoza, 2018; Chiurazzi, 2007; Escolano Benito, 2000; Castro y Serra, 2020). Nuestro abordaje lo realizamos desde una perspectiva interdisciplinaria ${ }^{3}$, para lo cual estamos construyendo una serie de categorías teórico-analíticas que nos posibilitan ir configurando una perspectiva interdisciplinar para leer y analizar la espacialidad en la escuela. Con los resultados de nuestra investigación pretendemos contribuir al desarrollo de una perspectiva para el análisis y estudio de la espacialidad en educación, considerando en este proceso los aportes y debates de las ciencias sociales, la pedagogía, la política educativa, como así también los registros e intervenciones que venimos desarrollando, como equipo interdisciplinario de arquitectos, pedagogos y diseñadores industriales, en escuelas públicas de la ciudad de Córdoba con las que estamos trabajando y forman parte de nuestro campo empírico.

En tal sentido, el presente artículo se estructura en dos partes. Una primera parte, en la que recuperamos ciertos desarrollos teóricos y analíticos de las ciencias sociales, especialmente de la geografía y la sociología, que se constituyen en insumos fértiles para la construcción de nuestros análisis. Tomar ideas, conceptos y categorías producidas en otros contextos disciplinares y ponerlos en juego para leer y abordar objetos de estudios en contextos diferentes, tiene el riesgo de producir lecturas lineales y forzar significados, somos conscientes de esta posibilidad, no obstante asumimos el desafío porque estas lecturas nos han posibilitado ampliar nuestro horizonte teórico y analítico, porque esta operación intelectual y metodológica, nos ha posibilitado abrir el campo de mira, hacernos otras preguntas, mirar otras aristas de nuestro objeto de conocimiento: la espacialidad en educación, y más específicamente el espacio escolar. En esta operación intelectual, que nos implica exigentes desafíos epistemológicos y metodológicos, el compromiso que asumimos como investigadores, es construir conectores, a modo de interlocución de sentidos entre estos conceptos e ideas producidos en diferentes campos de conocimiento y los usos que les damos en nuestro campo empírico y conceptual. Las ideas y categorías analíticas que recuperamos de otros campos, como el caso de la geografía, van sufriendo mutaciones y desplazamientos de sus sentidos "originales", dando lugar a otros posibles nuevos sentidos, en los vínculos e interacciones con otras categorías analíticas y el propio trabajo de campo realizado en el marco de nuestra investigación. Esto es lo que estamos construyendo en la primera parte del artículo y se profundiza en la segunda.

En la segunda parte del texto, nos acercamos al campo empírico, que como se dijo, implica los procesos de escolarización y los mecanismos que se ponen en marcha, tanto a nivel de las políticas como de las instituciones educativas, para garantizar el derecho a la educación y la obligatoriedad de la escuela secundaria, entendiendo que se trata de una construcción social y uno de los principales objetivos de la política pública educativa. En esta parte, planteamos algunas preguntas en torno a la vinculación entre estas políticas educativas y la espacialidad, recuperando y poniendo en juego el potencial analítico, descriptivo y explicativo del enfoque que estamos construyendo de forma interdisciplinaria en nuestra investigación. Somos conscientes que es una tarea que necesita seguir ampliándose y profundizándose, no obstante, hemos iniciado un camino, nuestro camino apostando a la investigación y al trabajo interdisciplinar, no exento de conflictos y disputas, pero también de mucha potencia para dar cuenta de realidades complejas que demandan de lecturas y análisis que no reduzcan y empobrezcan esa complejidad.

\section{¿DE QUÉ HABLAMOS CUANDO HABLAMOS DE ESPACIOS ESCOLARES?}

Existen diversidad de ideas, dimensiones, planos que podemos asociar al espacio escolar. En una primera aproximación enunciamos algunos aspectos que entendemos son aristas,

\footnotetext{
${ }^{3}$ En el equipo participan licenciados en ciencias de la educación, arquitectos, diseñadores industriales, psicólogos, geógrafos y estudiantes de estas carreras.
} 
facetas del espacio escolar y que nos posibilitan visibilizar el amplio campo de cuestiones vinculadas al significante "espacio escolar":

- El espacio escolar refiere a la arquitectura, a la materialidad del edificio escuela, a los límites y a las interacciones entre la escuela y el contexto barrio-ciudad-espacio público.

- El espacio escolar refiere a la relación entre cuerpos, objetos, edificios. A las relaciones de proximidad, distanciamiento, jerarquías, diferencias, articulaciones y desarticulaciones. A la conexión, desconexión entre puntos, partes y trayectorias.

- El espacio escolar es un dispositivo que ordena, encauza, regula, controla y produce cuerpos, representaciones y sentidos.

- El espacio escolar se refiere a un lugar institucional específico que la sociedad designa como lugar para la socialización y transmisión de saberes y conocimientos entre pares y generaciones.

- El espacio escolar es una dimensión, como la dimensión temporal, estructural y estructurante del dispositivo escolar que, en articulación con otros componentes, discursos y prácticas, configuran y consolidan la forma escolar moderna.

- El espacio escolar es parte de la matriz organizacional de la escuela, es una dimensión de los modos de ser y hacer escuela. Es un elemento constitutivo de la organización escolar y de la vida cotidiana de las escuelas.

- El espacio escolar es lo que los sujetos que habitan ese espacio hacen de él, no es solo la materialidad de los edificios sino los sentidos y significados construidos por los sujetos con relación a los espacios y la espacialidad.

Seguramente podemos seguir desplegando otros aspectos que refieren al espacio escolar, lo cual, podría hacernos concluir que una de las características del espacio escolar es la amplitud y diversidad de aspectos que implica y en este sentido, nos plantea el desafío de construir su especificidad. No obstante, entendemos que la construcción de esa especificidad o delimitación no implica necesariamente la reducción, entendida como identificación ajustada, y selectividad de los rasgos que lo configuran, sino que más bien se trata -y esta es nuestra opción- de un recorrido analítico que nos posibilite señalar que el significante "espacio escolar" refiere, y tiene la potencia de referir, a un amplio espectro de cuestiones, a la vez que es producto de un conjunto de interrelaciones y procesos que trataremos de no diluir, reducir, negar, invisibilizar en la reflexión que proponemos. Justamente, la invitación es a reconocer esa potencia y a construir esa espesura y densidad que creemos tiene el espacio escolar como objeto de conocimiento.

\section{LA DENSIDAD, LA ESPESURA, LA COMPLEJIDAD DEL ESPACIO ESCOLAR}

Desconocer el hecho de que, a pesar de su apariencia sedentaria, la educación es un nomadismo permanente de ideas, de gente, de problemas y coyunturas, sería negar su propia esencia. (Carlos Skliar, 2018)

Proponemos abordar la categoría espacio escolar en una trama de sentidos, que aportan las ciencias sociales, con la idea de abrir el análisis y la reflexión y dar cuenta de la espesura, densidad y complejidad que entendemos conlleva la construcción de esta categoría teóricoanalítica. Las ciencias sociales nos posibilitan ampliar la mirada pedagógica y plantear otras preguntas, considerar nuevas aristas, planos y relaciones. El objetivo es contribuir a la reflexión del espacio escolar e intentar producir lecturas del mismo que no simplifiquen su configuración ni operen reforzando su ocultamiento y naturalización sino más bien, desde una actitud crítica y de exploración cooperar a su conocimiento y estudio. 
Las preguntas que orientan nuestra búsqueda en el campo de las ciencias sociales son: ¿cómo conceptualizan el espacio las ciencias sociales?, ¿el espacio es aquello que se ocupa?, ¿es lo que contiene a las cosas?, ¿es una superficie?, ¿es un escenario o telón de fondo donde se suceden los actos o acontecimientos sociales?

Los aportes de la geografía fueron centrales en este camino, especialmente aquellos estudios surgidos luego de la revolución epistemológica del campo geográfico en la década de 1970, que problematizaron el espacio caracterizándolo como una elaboración social compleja y dinámica, dando paso a lo que se denominó giro espacial, caracterizado por su rechazo, crítica y generación de propuestas alternativas a la concepción de la geografía entendida como ciencia teorética cuantitativa de corte positivista ${ }^{4}$. Se trata de estudios críticos, que otorgan reconocimiento y visibilidad no sólo a la macro estructura y su influencia en los procesos sociales y geográficos sino fundamentalmente a aquellos que reconocen el papel de los sujetos y los contextos locales en la producción de acontecimientos sociales y geográficos (Massey, 1994, 2005, 2008; Gregory,1984; Harvey, 1998, entre otros). También indagamos en los aportes de geógrafos humanistas, que consideran en el análisis espacial, aspectos subjetivos, afectivos, estéticos y simbólicos en las relaciones entre los seres humanos y su entorno, en términos de lugar o espacio vivido (Tuan, 1977, 2003).

Un aporte fundamental en el abordaje desde las ciencias sociales lo constituyó la teoría de la producción social del espacio de Henri Lefebvre, -historiador, filósofo, urbanista- que realiza una propuesta relacional crítica, consistente en una articulación de diferentes formas de espacialidades: las representaciones del espacio, los espacios de representación y las prácticas espaciales.

Las posiciones de geógrafas y geógrafos como Doreen Massey, Derek Gregory, David Harvey, Allan Pred, Yves Lacoste, inspirados e influidos por sociólogos y urbanistas como Lefebvre y Castels, renuevan los debates y profundizan la necesidad de revalorizar el papel del contexto espacial en la explicación e interpretación de los procesos y fenómenos sociales, políticos y económicos ${ }^{5}$. Asimismo, critican y se distancian tanto de las posiciones que consideran al espacio como una especie de amorfo contenedor donde se dan cita procesos sociales diversos, como de otras que sostienen que el espacio y su organización son un mero reflejo de la estructura social, determinados por procesos económicos y sociales, donde la categoría espacio geográfico tendría bien poco o nada que decir. Estas formulaciones pueden interpretarse como respuesta desde la geografía a la teoría social, en especial, la reconsideración del papel dado a los agentes en la estructura. (Noguè i Font, 1989, p.66)

Como puede advertirse, estas producciones teóricas y metodológicas problematizaron el espacio considerándolo como algo más que el reflejo de la estructura social o un mero contenedor de las relaciones sociales, revalorizando el contexto espacial en la explicación e interpretación de los procesos y fenómenos sociales, políticos y económicos. Además, consideran ciertas particularidades, hasta entonces excluidas e ignoradas por la geografía positivista como el espacio como lugar vivido, lleno de significados para el ser humano, posicionando y revalorizando aspectos afectivos, sensoriales, estéticos y simbólicos de las relaciones entre los sujetos y su entorno, como el caso de la geografía de enfoque humanista.

\footnotetext{
4 Para estos estudios críticos, que se referencian en el giro espacial, el espacio emerge como un producto social configurado por medio de la yuxtaposición de recorridos, desplazamientos, discursos, prácticas, etc. configurando a la vez dinámicas sociales. El giro espacial no implicaría una inversión o transformación de los términos, en los cuales a partir de ello se plantea un neodeterminismo geográfico o una espacialización a ultranza del pensamiento social. Sino más bien "comenzar a entender el espacio como parte constitutiva de la vida colectiva y no sólo como marco estático de ésta” (Garzón, 2008:95)

${ }^{5}$ Michel Foucault en la conferencia de 1974 "Des espaces autres", en el Cercle des études architecturals, plantea que de la "época de la historia", signada por el tiempo como tema central para las filosofías y las ciencias de lo social, se habría transitado, durante la segunda mitad del siglo XX, hacia la "época del espacio".
} 


\section{LA CONSTRUCCIÓN DE UNA MIRADA SOBRE LA ESPACIALIDAD ESCOLAR}

A continuación, y recuperando estas perspectivas de las ciencias sociales, realizamos algunas reflexiones sobre el espacio escolar y la espacialidad en educación inspiradas en los aportes de Henri Lefebvre y Doreen Massey, los cuales son valiosos y potentes para ampliar y enriquecer el análisis de nuestro objeto.

El espacio escolar es una producción social, esto quiere decir que como construcción social está vinculado y atravesado por las ideas, disputas, tensiones y prácticas de la época y el contexto de que se trate. Existe interrelación permanente entre la dimensión espacial y temporal. En esta interrelación, el tiempo configura las relaciones y producción del espacio y a la vez el espacio produce subjetividades que se traducen en formas de ver, pensar, sentir, intervenir y estar en el mundo. Este cruce espaciotemporal es clave para analizar la vinculación entre la espacialidad y la escuela y cómo su configuración se explica por ciertos procesos sociales, económicos, políticos y culturales. Si consideramos por caso la escuela moderna observamos una determinada configuración del espacio producto de ideas educativas y posiciones pedagógicas, prevalecientes en ese contexto, que tiende a la especificación, a la división y a la jerarquización. Estos atributos se traducen en las construcciones escolares y en su uso. Se especifican los lugares donde se enseña diferenciándose de otros espacios indeterminados destinados a la función de enseñar en épocas anteriores. Se dividen y asignan funciones a los espacios escolares, aulas, patios, bibliotecas, jardines, casa del director o directora, etc. en contraposición a espacios indiferenciados. Se jerarquiza, según la pedagogía que se sustenta, el lugar del maestro, del profesor, del monitor y también ciertos objetos del dispositivo escolar, el escritorio o mesa del profesor, el pizarrón, el mástil y la bandera, etc. Estas cuestiones, junto a otras, como la constitución del campo pedagógico, la formación de un grupo de especialistas -maestros, profesores- para impartir la enseñanza, la determinación de un conjunto de conocimientos y currículos, van configurando la escuela moderna, como máquina de educar (Pineau, Dussel y Caruso, 2001) no sin contradicciones y tensiones tanto a su interior como con otras ideas y prácticas contemporáneas.

Entonces, decimos que el espacio no es una condición previa, sino que es el resultado de una actividad y, como planteamos, tiene una dimensión temporal. El espacio es producción social, no permanece estático, sino que es creador y creación de un conjunto de relaciones en transformación permanente en las cuales interviene de un modo incisivo ${ }^{6}$. Esta dimensión temporal, nos posibilita considerar interacciones, conexiones y resistencias de los espacios escolares con relación a ideas, prácticas sociales y culturales más allá de lo escolar, pero que influyen, atraviesan y configuran las espacialidades en educación.

Para Henri Lefebvre (2013) los conflictos y contradicciones sociales se plasman en la estructura urbana, de allí que hay una íntima relación entre la política y la vida cotidiana de los sujetos. Analiza la vinculación entre el espacio, el poder y los usos que del espacio se hacen, que muchas veces pareciera naturalizar un estado de las cosas, situación que impide ver las ideologías y posicionamientos en determinadas configuraciones y representaciones espaciales. En sus Reflexiones sobre la Política del Espacio, Lefebvre (1976) sostiene que el espacio no es un objeto científico separado de la ideología o de la política, sino que siempre ha sido político y estratégico. Si el espacio tiene apariencia de neutralidad e indiferencia frente a sus contenidos, y por eso parece ser puramente formal y el epítome de abstracción racional, es precisamente porque ya ha sido ocupado y usado, y ya ha sido el foco de procesos pasados cuyas huellas no son siempre evidentes en el paisaje. El espacio es político e ideológico. Es un producto literariamente lleno de ideologías. (Lefebvre, 1976, p.31 en Oslender, 1999, p.4)

\footnotetext{
${ }^{6}$ Henri Lefebvre formula la teoría de la producción social del espacio que se constituye en un gran aporte para los estudios urbanos. Estos escritos y reflexiones del autor coinciden con el auge del fordismo, fenómeno que, junto a otros, transforma el territorio capitalista dando lugar a una urbanización intensiva de los países centrales. En este sentido el autor hace una contribución para comprender la problemática emergente de la urbanización intensiva en un mundo capitalista desarrollado.
} 
Pensar que existen y se interrelacionan diferentes espacialidades en un territorio, como sostiene Lefebvre en La producción del espacio (2013), es desde nuestro punto de vista, uno de los aportes más destacados para construir una analítica del espacio escolar. Ello nos posibilita pensar el espacio escolar como un lugar en donde coexisten y se entrecruzan diversos tipos de espacialidades vividas, percibidas y representadas. Esta analítica del espacio escolar considera interrelacionada y simultáneamente los discursos, las representaciones y prácticas del espacio educativo en la experiencia cotidiana de vivir y transitar en él.

La idea de que existen diferentes espacialidades en juego, a veces interconectadas, otras veces distanciadas, con quiebres y tensiones entre sí, la resignificamos para sostener que en el análisis de la espacialidad escolar coexisten discursos y representaciones que modelan, otorgan sentido a formas espaciales escolares, tanto materiales como simbólicas, que operan poniendo en relieve o invisibilizando ciertos procesos y configuraciones de la escolarización. Pero que a su vez estas configuraciones, que son prácticas de espacialidad, influyen en los modos de pensar y percibir el espacio. Lefevbre dirá que la historia del espacio no coincide ni con el inventario de los objetos, ni con las representaciones y discursos, sino que una historia del espacio debe considerar espacios de representación y representaciones del espacio, los lazos entre sí, así como la práctica espacial ${ }^{7}$.

Tomamos a continuación estas tres formas de espacialidad y las ponemos en relación con el campo educativo, con los procesos de escolarización y con su potencial para pensar la espacialidad escolar.

Una primera forma de espacialidad la constituyen las representaciones del espacio. Según Lefebvre (2013) éstas refieren al espacio concebido, al "espacio de científicos, urbanistas, tecnócratas e ingenieros sociales" (p.97), son representaciones del espacio que derivan de una lógica particular y de saberes técnicos y racionales. Estos saberes están vinculados con las instituciones del poder dominante y con las representaciones normalizadas generadas por una 'lógica de visualización' hegemónica, representados por ejemplo en mapas, estadísticas, etc., produciendo visiones y representaciones normalizadas que existen en las estructuras estatales, en la economía, y en la sociedad civil. Esta legibilidad funciona como una simplificación del espacio a una superficie transparente. De esta manera se produce una visión particular normalizada que oscurece luchas, ambigüedades, y otras formas de ver, percibir e imaginar el mundo. Ella misma se autoriza como 'verdad' del espacio. De hecho, existen múltiples formas de desafíos y reapropiaciones del espacio por los actores sociales. Sin embargo, lo que hace esta conceptualización del espacio es consolidar la importancia creciente de formas dominantes de esta lógica de visualización y las relaciones de poder y saber que la reproducen y son reproducidas por ella. (Oslender, 1999)

En el campo educativo, esta forma de espacialidad, nos remite a ideas, relatos y teorías que en diferentes momentos históricos configuran los modos de mirar, concebir y accionar en la espacialidad educativa. Un ejemplo de ello son los discursos pedagógicos normalistas de fines del siglo XIX sobre el espacio escolar con sus sistemas de distribución del poder en las que reconocemos posiciones centrales (ocupadas por los adultos) y otras periféricas, la monumentalidad de los edificios como formas de comunicación del sentido asignado socialmente a la educación y, el higienismo como la hegemonía del enfoque médico en la validación de la construcción de edificios escolares. Otros ejemplos más cercanos a nuestro tiempo, los constituyen el ingreso a la agenda de las políticas de infraestructura escolar de los discursos sobre accesibilidad, diseño universal y seguridad en la arquitectura escolar que implican formas específicas de inclusión educativa y regulan posiciones y efectos respecto del cuidado de los cuerpos en los espacios instituciones; así mismo, otro ejemplo lo observamos en el diseño arquitectónico de las escuelastipo, edificios idénticos entre sí, implantados indistintamente en espacios centrales o periféricos, rurales o urbanos, sin considerar cuestiones climáticas, del territorio, culturales y sociales.

\footnotetext{
7 Se trata de una propuesta de análisis relacional entre lo percibido, lo concebido y lo vivido, fundamentado en la concepción de que el espacio es a la vez material y representación mental.
} 
Estos son algunos ejemplos que a lo largo de la historia de la escolarización funcionaron y algunos de ellos aún funcionan como discursos dominantes de visualización con efectos en las representaciones sobre el espacio escolar. Cada uno de ellos se fue consolidando, apoyándose en argumentos científicos, saberes especializados y apelando a una 'verdadera' representación, que en muchos casos actúa y tiene efectos de naturalización y ocultamiento de las ideologías que la sustentan. En ocasiones la naturalización de espacio escolar es tal que actúa como una "verdadera" ideología que impide pensar en otros modos de configuración del propio espacio. Se trata de un efecto perfomativo de estas representaciones sobre otras representaciones posibles.

La segunda forma de espacialidad la constituyen los espacios de representación. Lefebvre define los espacios de representación como “...vividos a través de las imágenes y los símbolos que lo acompañan" (2013, p.98). Estos espacios tienen por origen la historia, contienen los lugares de pasión y de acción, los de las situaciones vividas, son cualitativos, fluidos y dinámicos.

Los espacios de representación refieren a la dimensión mental del mismo, a cómo los individuos perciben, imaginan, valoran el espacio. El conjunto de estas percepciones y valoraciones producen espacio, de allí su importancia de considerarlo en el análisis. Los espacios de representación están vinculados a la experiencia cotidiana de vivir en el espacio, son los espacios vividos. Oslender (1999) dirá que son formas de conocimiento locales, menos formales; dinámicas, simbólicas y saturadas con significados, construidos y modificados en el transcurso del tiempo por los actores sociales. Las resistencias, la producción de espacios contrahegemonicos, se ubican en esta dimensión de la triada. Lefebvre lo llamará "sitios de resistencia". En estos espacios encontramos una gran variedad de 'contra-discursos', en el sentido de Foucault, presentados por actores que se niegan a reconocer y a aceptar el poder hegemónico. (Oslender, 1999, p.7)

Por su parte, el antropólogo y geógrafo David Harvey caracteriza los espacios de representación como "invenciones mentales (códigos, signos, discursos espaciales, proyectos utópicos, paisajes imaginarios y hasta construcciones materiales, como espacios simbólicos, ambientes construidos específicos, cuadros, museos, etc.) que imaginan nuevos sentidos o nuevas posibilidades de las prácticas espaciales.” (Harvey, 1998, p. 244)

Pensar esta forma de espacialidad en la escuela nos posibilita reconocer, relevar y analizar el espacio escolar como espacio imaginado, valorado e intervenido por los sujetos, a través de símbolos, imágenes e intercambios de la vida cotidiana. Los espacios de representación tienen entre sus rasgos la fragmentación, cierta desconexión y laxitud propia de los discursos o configuraciones en formación, que es sin duda la posibilidad de aparición de otros espacios, otros registros, otras (des)conexiones.

En la espacialidad escolar los espacios de representación son ideas y materializaciones que implican otros modos, otras formas de concebir y producir el espacio, son producciones que interpelan las formas naturalizadas del espacio escolar tradicional normalizado y reificado, a su vez, estos espacios de representación también son interpelados, atravesados, tensionados por las transformaciones culturales y experiencias de subjetivación contemporáneas. A los espacios de representación en la escuela los leemos en las (des)articulaciones y tensiones con los regímenes de visualización de lo espacial -que desarrollamos en párrafos anteriores- y también en las experiencias y posiciones de la propia escuela en su propuesta de enseñanza y aprendizaje y definiciones curriculares, en las interacciones con el barrio, la comunidad, las culturas, las creencias, los valores y las prácticas. Hemos conocido algunas experiencias escolares que significan un desplazamiento o dislocamiento de los tradicionales sentidos y usos del espacio escolar, algunas suponen experiencias que salen de la materialidad del edificio escolar y circulan por otros espacios, ya sea en el espacio público abierto o en otras instituciones. Estas experiencias tienen un rasgo en común: la apropiación del espacio por parte de los actores implicados como posibilidad de construcción de otros sentidos de la espacialidad. No obstante, las formas de espacios de representación como espacialidades otras, son difíciles de visibilizar, de registrar. Esta cuestión es abordada por la pedagoga Silvia Serra y la arquitecta Margarita Trlin cuando plantean, como producto de una extensa investigación en la provincia de Santa Fe, que en diferentes momentos de la historia 
educativa provincial se han producido experiencias pedagógicas innovadoras y de vanguardia, pero que es muy difícil dar cuenta y reconocer en qué medida los edificios escolares donde se produjeron estas experiencias se vieron interpelados y modificados. Coincidimos con las autoras en que esto abre una línea de indagación que se orienta a conocer "por qué el espacio opera convencionalmente en la implementación de propuestas pedagógicas de vanguardia" (Serra y Trlin, 2014, p.28)

La tercera, y ultima forma de espacialidad son las prácticas espaciales. Estas están asociadas al espacio percibido, a la realidad cotidiana y a la realidad urbana. "La práctica espacial moderna se define, por lo tanto, por la vida cotidiana de un habitante" (Lefebvre, 2013, p.97). Por su parte, David Harvey plantea que las prácticas (materiales) espaciales son las transferencias e interacciones físicas y materiales que ocurren en y cruzando el espacio para asegurar la producción y reproducción social, que "nunca son neutrales en cuestiones sociales. Siempre expresan algún contenido de clase o social y, en la mayor parte de los casos, constituyen el núcleo de intensas luchas sociales" (Harvey, 1998, p.265). Para Oslender (1999) las prácticas espaciales se refieren a las formas en que generamos, utilizamos y percibimos el espacio. Por un lado, se efectúan los procesos de comodificación y burocratización de la vida cotidiana, un fenómeno que Lefebvre considera sintomático y constitutivo de la modernidad y que ha ido colonizado el espacio social. Sin embargo, por el otro lado, estas prácticas espaciales están íntimamente vinculadas con las experiencias de la vida cotidiana y las memorias colectivas de formas de vida diferentes. Por eso llevan un potencial para resistir esta colonización de los espacios concretos. Lefebvre dirá que las prácticas espaciales tienen una doble modalidad, la dominación y la apropiación.

Pensar las prácticas de espacialidad en los espacios escolares, en este doble registro de dominación y apropiación, nos posibilita analizar lo que sucede en las escuelas en términos de dominación y apropiación de los espacios, concentrarnos en los espacios y tiempos que han territorializado y territorializan el espacio escolar, sustentados en saberes, poderes y formas hegemónicas, no solo del campo pedagógico sino también del social, político, cultural y económico y los modos o formas de apropiación de esos espacios que los actores construyen, en oposición, diferenciación, o traducción y re significación en el intento por hacer otro/s uso/s por fuera del instituido.

Como ya dijimos, consideramos que la propuesta de Lefebvre es un valioso aporte a los efectos de una analítica del espacio, una perspectiva potente para el estudio del espacio en general y en nuestro caso particular, del espacio escolar. En el marco de su modelo relacional entre diferentes formas de espacialidades nos preguntamos ¿cómo es la práctica espacial escolar?, ¿existe un estilo dominante en esta práctica del espacio material?, ¿cómo se estructura y dispone esta práctica o prácticas del espacio escolar?, ¿cómo se configura el espacio escolar, como espacio representacional, en la experiencia cotidiana de los sujetos?, ¿qué relación o relaciones se pueden establecer entre prácticas espaciales y vivencias cotidianas de los sujetos?

Otro aporte, en este caso desde la geografía, es el de la geógrafa marxista crítica y feminista Doreen Massey. En un artículo publicado en el año 2005 y denominado "Filosofía y política de la espacialidad: algunas consideraciones", la autora propone una forma de definir al espacio y reconoce que éste es una de las cosas más obvias que se movilizan como término en una infinidad de contextos distintos, pero cuyos significados potenciales son raramente tematizados o explicitados.

Para construir una definición la autora presenta tres proposiciones de cómo podría conceptualizarse el espacio. Una primera proposición sostiene que el espacio es producto y se constituye a partir de interrelaciones, desde lo inmenso global hasta lo ínfimo de la intimidad. La segunda proposición sostiene que el espacio es la esfera de la posibilidad de la existencia de la multiplicidad, es donde coexisten distintas trayectorias, es la esfera que hace posible la existencia de más de una voz. "Sin espacio, no hay multiplicidad; sin multiplicidad, no hay espacio...son coconstitutivos" (Massey, 2005, p.105). La tercera proposición expresa que, porque justamente el espacio es producto de las relaciones, relaciones que están necesariamente implícitas en las 
prácticas materiales que deben realizarse, siempre está en proceso de formación, en devenir, nunca acabado, nunca cerrado.

$\mathrm{Su}$ aporte nos posibilita ir construyendo algunas reflexiones en torno a las preguntas planteadas al inicio de este articulo tales como si el espacio es una superficie sobre la cual los sujetos sociales transitan sus vidas o un telón de fondo sobre el que se despliegan los acontecimientos sociales. Por lo dicho, en el párrafo anterior, es obvio su desacuerdo con esta caracterización del espacio. Massey, más bien nos acerca a una definición del espacio como una configuración abierta, que contiene relaciones existentes y futuras, siempre cambiantes y por realizar. Dirá que el espacio es la esfera del (des)encuentro entre trayectorias, un lugar en donde éstas co-existen, se influyen mutuamente y entran en conflicto, por ello el espacio siempre está en proceso de realización, siempre tiene algo de caótico -aquello no prescripto aún por el sistema. "Es la esfera de la yuxtaposición potencial de los diferentes relatos, de forjamiento de relaciones nuevas. La espacialidad es también una fuente para la producción de nuevas trayectorias, nuevas historias" (Massey, 2005, p.121).

Podemos avanzar en esta línea de conceptualización sobre el espacio y plantear que se trata de una formación existente y potencial, o sea un conjunto de interacciones que están siendo, y también la esfera de otras vinculaciones potenciales. Esto significa que se trata de una concepción de espacio como apertura, potencialidad y permanente formación de relaciones. Desde una perspectiva crítica, que nos interesa sostener, recuperamos la idea de lo caótico, como aquello que aún no ha sido capturado por el sistema y la norma, y en este sentido es posibilidad de creación de algo nuevo, de dislocamiento de lo existente. Si pensamos la espacialidad escolar con esta perspectiva la inscribimos en una tradición que reconoce aquellos, gestos, elementos, vínculos e ideas, que por más minúsculos que fueran, producen un desplazamiento de las configuraciones consolidadas y hegemónicas.

A la luz de estos aportes, conjeturamos que el espacio escolar no es el mero reflejo de la estructura social, ni un escenario donde se juega o representa un juego social, sino más bien, un contexto espacial específico, en movimiento y configuración permanente. Es materialidad a la vez que potencia, construcción social y subjetivación. Se trata de una configuración de interrelaciones, a la vez que producto de esas interrelaciones, que implica la multiplicidad, la conexión y desconexión, la superposición de trayectorias, historias, relatos y experiencias que se producen en relación con la sociedad de la que es parte, pero no es el mero reflejo de lo que en ella sucede. Porque el espacio escolar como lugar implica considerar los sentidos y significados que los sujetos construyen en torno a él en un contexto social e histórico específicos. En este contexto espacial específico, podemos reconocer una multiplicidad de espacialidades, en términos de materialidades, representaciones y vivencias, que nos permite pensar el espacio escolar como una realidad social específica atravesada por discursos, materialidades, poderes, intereses, ideologías y prácticas en disputa y tensión, en su reificación y los intentos de desnaturalización de este.

\title{
LAS POLÍTICAS DE INCLUSION EDUCATIVA, EL DERECHO A LA EDUCACIÓN Y LA PRESENCIA DE LO ESPACIAL EN LA CONTRUCCION DE ESE DERECHO EN ARGENTINA
}

\begin{abstract}
Si una historia va a tener algún tipo de autenticidad, tendrá que estar peligrosamente cerca de lo que está contando. Y, al mismo tiempo, tendrá que estar asombrosamente lejos porque de otro modo lo que está describiendo no encontrará su medida en la escala humana. Por ende, tenemos este continuo ida y vuelta, íntimamente cerca y muy distantes. (John Berger, 2007, p.52)
\end{abstract}

En Argentina, de forma similar a lo sucedido en otros países latinoamericanos, en las últimas décadas se han aprobado legislaciones e implementado políticas públicas educativas que 
amplían la escolarización de la población, ya sea extendiendo la obligatoriedad de los años en diferentes niveles del sistema educativo o incrementando la cantidad de horas de la jornada y el tiempo escolar. La Ley de Educación Nacional N² 26.206 (LEN) sancionada en el año 2006 en Argentina, amplia a más años la obligatoriedad del nivel inicial, amplía a su totalidad la obligación de la escuela secundaria e incrementa la carga horaria en la escuela primaria con la modalidad de Jornada extendida o ampliada.

Estas propuestas de políticas públicas que van en la dirección de extender y garantizar el derecho a la educación de la población prevista en la propia ley, se valen de un conjunto de medidas, estrategias y acciones denominadas políticas de inclusión educativa ${ }^{8}$. Uno de los principales desafíos es la inclusión en los procesos de escolarización ${ }^{9}$ de los sectores que históricamente han estado excluidos (Nóvile, 2016), por lo cual las acciones y decisiones, en el marco de lo previsto en las normativas, giran en torno a cómo garantizar este derecho. Es así que nos preguntamos: ¿Qué acciones y decisiones tienden y posibilitan la concreción del derecho a la educación?, ¿qué condiciones son necesarias desplegar para garantizar el ejercicio de ese derecho?

Entendemos que estas son preguntas estructurales y estructurantes de la política educativa en el contexto actual. Es en este sentido, que las recuperamos para vincularlas a nuestras reflexiones sobre el espacio y la espacialidad escolar. En nuestra investigación, consideramos como parte del campo empírico, los textos políticos, que expresan las políticas educativas y también lo que acontece en la construcción de sentidos y traducciones operadas, en diferentes escalas del sistema educativo y las escuelas, por parte de los actores sociales implicados en esos procesos. Esta opción teórico-metodológica, como se dijo al inicio del artículo, la realizamos desde una mirada relacional, que intenta no simplificar estos procesos, atendiendo a la vez esferas macropolíticas y el análisis de micropolíticas presentes en diferentes instancias del proceso de desagregación de las políticas.

En este apartado, compartimos algunas reflexiones que, de forma relacional, venimos construyendo entre los mandatos de inclusión educativa y la construcción de espacialidad en las instituciones escolares. El objetivo es dilucidar cómo y de qué maneras lo espacial se articula o desarticula con estos propósitos de la política educativa. Por lo que, si traducimos las interrogaciones planteadas en un apartado anterior, en clave espacial podemos expresarlas de la siguiente forma: ¿Cómo se resuelve la extensión de la obligatoriedad en clave espacial en las escuelas? ¿Qué implicancias tiene la inclusión educativa a nivel espacial? ¿Cómo se resuelve espacialmente la extensión o ampliación de jornada en la escuela primaria? ¿Cómo pensar escuelas secundarias para todos?

En las primeras aproximaciones realizadas en nuestra investigación, abrimos el juego a las ciencias sociales, en dialogo con los aportes de la pedagogía y la política educativa, en su potencial aporte para leer y analizar la dimensión espacial en los procesos educativos y escolares.

Como ya se ha señalado, Henri Lefebvre en La producción del espacio, habla de las prácticas espaciales y dice que en las relaciones que los grupos humanos entablan con el medio espacial siempre existen relaciones de poder, las cuales tiene dos modalidades: la dominación y la apropiación. La dominación del espacio se caracteriza a partir del vínculo con el saber y el influjo

\footnotetext{
8 “Garantizar la inclusión educativa a través de políticas universales y de estrategias pedagógicas y de asignación de recursos que otorguen prioridad a los sectores más desfavorecidos de la sociedad.” (LEN, Art. 11, inc. e)

${ }^{9}$ Es importante preguntarse por los sentidos y formas de los procesos de inclusión educativa. Para ampliar sobre este aspecto puede consultarse Dussel (2004) que recupera a Popkewitz (1991, p.4), cuando sostiene que la cuestión de la inclusión es un proyecto político fundamental en sociedades que han excluido sistemática y categóricamente a grupos sociales. Tal como lo dice este autor, la manera en que hemos concebido la inclusión quizás sea el "crimen" que debemos investigar, y no sólo la falta de "acceso" de algunas poblaciones a la institución escolar. Así, dice Dussel "considero que las preguntas que deberían guiar nuestra reflexión sobre la exclusión educativa en nuestras sociedades son las siguientes: ¿en qué sistema escolar queremos incluir a todos? ¿No es acaso la organización actual de la escuela la que ha producido buena parte de las exclusiones? ¿Cómo puede re-examinarse esta institución, conservando el sueño de educar a todos pero evitando reproducir las mismas injusticias?”
} 
político y económico, o sea, una transformación técnica y práctica de la naturaleza que acaba territorializando en el espacio un poder. Y, en contraposición, pero en relación dialéctica, se sitúan las prácticas de apropiación, que están asociadas a un aspecto más subjetivo, cultural y simbólico de las mismas, al uso del espacio, a los símbolos y tiempos generados por parte de los sujetos que construyen su territorialidad (Haesbaert, 2004). Asimismo, Lefebvre plantea que el habitar para un individuo o para un grupo, es apropiarse de algo. Apropiarse no es tener en propiedad, sino hacer su obra, modelarla, formarla, poner el sello propio.

En nuestro estudio sostenemos que habitar es apropiarse del espacio. Por ello, procuramos identificar en ese proceso la creación de usos particulares, como así también huellas y marcas que denoten esos usos particulares.

Creemos que las ideas de dominación y apropiación de las prácticas espaciales, como la de habitar, son potentes para pensar las preguntas que nos hacemos respecto a ¿cuáles son las acciones y decisiones de la política educativa para garantizar el derecho a la educación y qué condiciones de la dimensión espacial favorecen su ejercicio?, ¿cómo se traducen estos propósitos de la política educativa en clave de espacios escolares?

Una conjetura que planteamos es que la extensión de los años de escolarización (tanto en el nivel inicial como en el nivel secundario) o la permanencia por más horas en la escuela (jornada extendida en las escuelas de nivel primario) como acciones para la inclusión educativa, desembarcan en las escuelas con la fuerza de la territorialización, esto es la fuerza de la ley que reconoce y amplía el derecho a la educación para todos. No obstante, observamos que la ley por sí sola no garantiza el ejercicio del derecho. Obviamente la sanción de la ley es un hito importante y crucial en la universalización de los derechos, pero no es suficiente. Es necesaria la construcción de condiciones para el ejercicio de ese derecho. En otras palabras, es posibilitar que la ley comience a encarnarse, a hacerse cuerpo en los diferentes agentes, grupos e instituciones en las diferentes escalas del aparato burocrático-estatal, del sistema educativo y de las escuelas. Se trata de la construcción de territorialidad, por parte de los actores sociales, de esas decisiones políticas en las escuelas. Es decir, habilitar y posibilitar su apropiación, entendida como proceso de asignación de sentidos por parte de las comunidades y los actores en la construcción de territorialidad, de habitabilidad, producir marcas particulares en la apropiación de la extensión y obligatoriedad de la escolarización.

Concebir el pasaje del derecho a la educación como mandato (como fuerza de territorialización) a su apropiación (como construcción de territorialidad por parte de los sujetos), abre la posibilidad de pensar la inclusión y permanencia de los estudiantes en las escuelas como construcción de habitabilidad, como proceso de apropiación, de uso del espacio, que se concibe, se siente y se vive como propio. En este punto, es interesante repensar la inclusión educativa, entendiéndola no solo como la inclusión de los estudiantes en un sistema escolar, en un formato escolar ya dado, sino también la inclusión como correlato de la construcción de esa habitabilidad, en el cual los sujetos tienen un rol activo y participan de procesos de producción y transformación. Esta habitabilidad no implica solo pensar la inclusión educativa como el ingreso, la permanencia y el egreso de los estudiantes en la escuela existente, sino también modificar aquello que, en muchos casos, ha sido parte del problema del sistema educativo en sus efectos de exclusión, tales como los formatos escolares rígidos en sus tiempos y espacios, la concepción de un alumno ideal distante a las diversas realidades de las niñas, los niños y jóvenes reales, sistemas de evaluación que priorizan solo los resultados, entre otros aspectos necesarios de analizar y modificar.

Entre las dos prácticas espaciales señaladas, la de dominación y la de apropiación, se producen una serie de intermediaciones que podemos identificar como acciones de resistencia, traducción, asimilación y transformación por parte de los sujetos en los procesos de escolarización e inclusión en la escuela, que posibilitarían habitar, hacer propias, estas nuevas circunstancias y prácticas escolares que se configuran bajo la modalidad de obligación a partir de la sanción de la ley. 
Desde nuestra perspectiva, que es en defensa de la escuela pública y el compromiso por mejorar los procesos de escolarización, uno de los desafíos es construir y enriquecer la habitabilidad de la escuela para garantizar el ejercicio del derecho a la educación de la población. Según Lefevbre (2013), en el juego entre territorialización y construcción de territorialidad por parte de los sujetos se juega la tensión entre constreñimiento y apropiación. En nuestro caso, el constreñimiento significaría reproducir las formas tradicionales del formato escolar, limitarse, ceñirse -tanto en la acción como en el pensamiento- a lo dado, mientras que la apropiación, sin desconocer el peso de esta tradición, arriesga y explora otros sentidos y usos del formato escolar, de ese dispositivo organizacional, desde una posición crítica de desnaturalización y de pensamiento creativo y situado. La tensión entre constreñimiento y apropiación es permanente, no se resuelve de una vez y para siempre, sino que son fuerzas que actúan, encarnadas en proyectos, dispositivos y actores sociales y que dependen de las relaciones de fuerza y poder relativos y desplegados en cada situación y contexto.

Por lo dicho, es necesario sostener una mirada que desnaturalice, que se pregunte por los efectos de inclusión/exclusión de las formas escolares tradicionales y cómo revertir los efectos de exclusión de esos formatos instituidos que han sido y en muchos casos son altamente eficaces. Pero también estar alertas para no reproducir en las nuevas formas mecanismos de exclusión. La inclusión educativa implica la incorporación de aquellos niños, adolescentes y jóvenes que no accedieron a la escuela primaria y secundaria o que la han abandonado. Durante mucho tiempo imperó, y aún subsiste, la concepción de que el abandono o la no incorporación a la escuela era consecuencia de dificultades de los propios niños y jóvenes, ya sea por su pertenencia a determinados sectores sociales y culturales y/o por problemáticas individuales. Poco se interpelaba al sistema educativo, a la política educativa y a la propia escuela como participes y con responsabilidad en esa situación. Es en tiempos más recientes, con la preocupación creciente por la inclusión de la población a la escuela secundaria, y con legislaciones que garantizan el derecho a la educación, que se ha comenzado a interrogar al sistema educativo y a la propia escuela, a su formato y a la cultura escolar, como partícipes de la exclusión. Esta es una transformación en el modo de pensar el problema que impacta, aunque no necesariamente, en la formulación, las estrategias de abordaje y las posibles soluciones al mismo. Esta mutación en el enfoque está sucediendo, pero aún falta mucho por hacer y en este sentido las ciencias sociales tienen mucho por aportar.

Ojalá con este texto aportemos, desde la investigación, a la (re)conceptualización y análisis de la dimensión espacial en las políticas educativas y en la escuela. Seguramente hay mucho todavía por andar y producir en este campo interdisciplinario de la espacialidad educativa y escolar.

\section{REFLEXIÓN FINAL}

Quisiera terminar este escrito con una idea metáfora, que condensa algunos de los sentidos que hemos intentado desplegar en este artículo en torno a las escuelas y la espacialidad. Concebir la espacialidad escolar como palimpsesto ${ }^{10}$ implica considerar la multiplicidad de interacciones que tienen lugar en la escuela, las conexiones y desconexiones entre el pasado y el presente, la porosidad de las fronteras con los procesos sociales y culturales y los efectos de erosión y preservación que estos intercambios producen y tienen el potencial de producir. La espacialidad escolar está en constante proceso de reescritura, en constante movimiento de configuración y reconfiguración de sus formas y modos de existencia. En estos modos y formas percibimos rasgos y signos de otros tiempos, que podemos llamar anacronismos espaciales, pero que no se conservan inalterados, sino que existen en tensión e intersección con otros modos actuales de espacialidad. Existen espacialidades diversas, de diferentes sentidos y significados construidos por los sujetos

10 Se llama palimpsesto al manuscrito que todavía conserva huellas de otra escritura anterior en la misma superficie, pero borrada expresamente para dar lugar a la que ahora existe. 
sociales, que producen espacialidad y a su vez se ven afectados por esas mismas espacialidades en sus representaciones del espacio y en la producción de conocimiento en torno al mismo. Pensar la espacialidad escolar como palimpsesto implica, además, reconocer el nomadismo como una forma de la espacialidad en la escuela que interpela y reconfigura la concepción moderna ilustrada del espacio escolar como fijo, cerrado, normalizado y racional que caracteriza el surgimiento de la escuela y los sistemas educativos modernos. No se trata de negar o desconocer la presencia de esa concepción fija y sus efectos sobre la espacialidad escolar, especialmente en sus efectos de encausamiento, reificación y naturalización, sino más bien reconocer la multiplicidad de capas y de interacciones que configuran la espacialidad en las formas escolares.

\section{REFERENCIAS}

BAQUERO, R., DIKER, G. y FRIGERIO, G. Las formas de lo escolar. Buenos Aires: Del estante editorial/Centro de Estudios Multidisciplinarios, 2007.

BERGER, J., SERRA BRADFORD, M. y HARVEY, D. Boulevard Central. Buenos Aires: Edhasa, 2007.

CASTRO, A. y SERRA M. F. "Espacio escolar y utopía universalizadora. Definiciones, tensiones y preguntas en torno a lo espacial y la ampliación del derecho a la escolaridad". Revista Perfiles Educativos, Instituto de Investigaciones sobre la Universidad y la Educación (IISUE), UNAM. Ciudad de México (en prensa).

CASTRO, A. y OLIVA, S. Espacialidad y educación: reflexiones y experiencias desde la investigación. 1a ed. Córdoba: FAUDI - FFyH -Universidad Nacional de Córdoba, 2020.

CATTÁNEO, D. y ESPINOZA, L. "Arquitectura escolar e historia. Repaso sobre enfoques, problemas y proyectos", ponencia presentada en "VIII Encuentro de Docentes e Investigadores en Historia del Diseño, la Arquitectura y la Ciudad", Universidad Nacional de Córdoba, Córdoba, 2018.

CHIURAZZI, T. Arquitectura para la educación. Educación para la arquitectura. En: Baquero, Diker y Frigerio (Comp.) Las formas de lo escolar. Buenos Aires: Del estante editorial/Centro de Estudios Multidisciplinarios, 2007, p. 45-58

DUSSEL, I. Inclusión y exclusión en la escuela moderna argentina: una perspectiva postestructuralista. Cadernos de Pesquisa [online] vol.34, n. 122, p.305-335, 2004. Disponible en: http://dx.doi.org/10.1590/S0100-15742004000200003.

ESCOLANO BENITO, A. Tiempos y espacios para la escuela. Ensayos históricos, Madrid, Editorial Biblioteca Nueva, 2000.

FOUCAULT, M. Crítica y Aufklärung [“Qu'est-ce que la Critique?’]. Revista de Filosofía-ULA, 8, p.1-18, 1995. Disponible en: URI http://www.saber.ula.ve/handle/123456789/15896, 1995.

FOUCAULT, M. "Des espaces autres", Conferencia dictada en el Cercle des études architecturals, 14 de marzo de 1967. Architecture, Mouvem ent, Continuité, Paris, n.5, p.46-49, 1984. Versión digital: http://www.fadu.edu.uy/estetica-diseno-i/files/2017/07/foucalt_de-los-espaciosotros.pdf

GARZÓN MARTÍNEZ, M. El lugar como política y las políticas del lugar. Herramienta para pensar el lugar. Signo y Pensamiento, Vol. XXVII, Bogotá: Pontificia Universidad Javeriana, n. 53, p. 93-103, 2008. 
GREGORY, D. Ideología, ciencia y geografía humana.Vilassar de Mar, Barcelona: Oikos-Tau, 1984.

HAESBAERT, R. O mito da desterritorializção: do "fim dos territórios" á multiterritorialidade. Rio de Janeiro: Bertrand Brasil. 2004.

HARVEY, D. La experiencia del espacio y del tiempo. En: Harvey, D. La condición de la posmodernidad. Buenos Aires: Amorrortu, 1998, p.225-356.

LEFEBVRE, H. La producción del espacio. Madrid: Capitán Swing, 2013.

LEFEBVRE, H. Reflections on the Politics of Space. Antipode, v. 8, n. 2, p. 30-37. https://doi.org/10.1111/j.1467-8330.1976.tb00636.x, 1976.

MASSEY, D. Space, Place and Gender. Oxford: Blackwell, 1994.

MASSEY, D. La filosofía y la política de la espacialidad: algunas consideraciones. En: Arfuch, L. (comp.). Pensar este tiempo. Espacios, afectos, pertenencias. Buenos Aires: Paidós, 2005.

MASSEY, D. Pelo Espaço. Uma Nova politica da espacialidades. Rio de Janeiro: Editora Bertrand Brasil Ltda, 2008.

NOGUÈ I FONT, J. Espacio, lugar, región: hacia una nueva perspectiva geográfica regional. Boletín de la Asociación de Geógrafos Españoles, Madrid: Asociación Española de Geografía, n. 9, p.49-62, 1989. En línea: http:// dialnet.unirioja.es/servlet/articulo?codigo=1318196.

NOVILE, M. La escuela secundaria obligatoria en Argentina: desafíos pendientes para integrar a todos los jóvenes. Ultima Década N44, Proyecto Juventudes, p. 109-131. Departamento de Sociología de la Facultad de Ciencias Sociales de la Universidad de Chile, Santiago de Chile, 2016.

OSLENDER, U. Espacializando resistencia: perspectivas de 'espacio' y 'lugar' en las investigaciones de movimientos sociales. Cuadernos de Geografía. Bogotá, vol. 8, n. 1, p.1-35, 1999. Disponible en: https://revistas.unal.edu.co/index.php/rcg/article/view/71603.

PINEAU, P., DUSSEL, I., CARUSO, M. La escuela como máquina de educar. Tres escritos sobre el proyecto de la modernidad. Buenos Aires: Editorial Paidós, 2001.

SERRA, M. S. y TRLIN, M. “Trazos de emancipación en las estrategias de apropiación del espacio. Las Escuelas de la Familia Agrícola correntinas del Taragǘ', ponencia presentada en The International Standing Conference for the History of Education - ISCHE, 2017

SKLIAR, C. Entrevista realizada por Franco, F., Gutiérrez, F. La Diaria - Educación, 3 de mayo 2018. Disponible en: https://educacion.ladiaria.com.uy/articulo/2018/5/academico-consideraque-se-debe-poner-el-foco-en-como-ensenar-a-cualquiera-antes-que-en-aprendizajes-singulares /

TRLIN, M., SERRA, S. Encuentros y desencuentros entre innovaciones educativas y espacio escolar en la provincia de Santa Fe. En: Cabrera, Trlin y Serra (comp.) Proyectando escuelas primarias no graduadas. Articulaciones pedagógicas y arquitectónicas en procesos educativos alternativos. Santa Fe: Universidad Nacional del Litoral, 2014.

TUAN, Y. F. Espacio y Lugar. La perspectiva de la experiencia. Minnesota: University of Minnesota Press, 1977. 